\section{Comparison of diagnostic sensitivity and specificity of seven Cryptosporidium assays used in the UK}

\author{
Correspondence \\ Rachel M. Chalmers \\ Rachel.chalmers@wales.nhs.uk
}

Received 9 May 2011

Accepted 12 July 2011

\author{
Rachel M. Chalmers, ${ }^{1}$ Brian M. Campbell, ${ }^{2}$ Nigel Crouch, ${ }^{1}$ André Charlett ${ }^{3}$ \\ and Angharad P. Davies ${ }^{1,2}$
}
${ }^{1}$ UK Cryptosporidium Reference Unit, Public Health Wales Microbiology, Singleton Hospital, Swansea SA2 80A, UK NW9 5DF, UK

${ }^{2}$ Institute of Life Sciences, School of Medicine, Swansea University, Swansea SA2 8PP, UK

${ }^{3}$ Statistics Unit, Health Protection Agency Centre for Infections, 61 Colindale Avenue, London

To compare the diagnostic sensitivity and specificity of seven Cryptosporidium diagnostic assays used in the UK, results from 259 stool samples from patients with acute gastrointestinal symptoms were compared against a nominated gold standard (real-time PCR and oocyst detection). Of the 152 'true positives', 80 were Cryptosporidium hominis, 68 Cryptosporidium parvum, two Cryptosporidium felis, one Cryptosporidium ubiquitum and one Cryptosporidium meleagridis. The Cryptosporidium spp. diagnostic sensitivities of three Cryptosporidium and Giardia combination enzyme immunoassays (EIA) coupled with confirmation of positive reactions were $91.4-93.4 \%$, whilst the sensitivity of auramine phenol microscopy was $92.1 \%$ and that of immunofluorescence microscopy (IFM) was $97.4 \%$, all with overlapping $95 \%$ confidence intervals. However, IFM was significantly more sensitive ( $P=0.01$, paired test of proportions). The sensitivity of modified Ziehl-Neelsen microscopy was $75.4 \%$, significantly lower than those for the other tests investigated, including an immunochromatographic lateral flow assay (ICLF) (84.9\%) $(P=0.0016)$. Specificities were $100 \%$ when the ICLF and EIA test algorithms included confirmation of positive reactions; however, four positive EIA reactions were not confirmed for either parasite. There was no significant difference in the detection of C. parvum and C. hominis by each assay, but the detection of other Cryptosporidium spp. requires further investigation, as the numbers of samples were small. ElAs may be considered for diagnostic testing, subject to local validation, and diagnostic algorithms must include confirmation of positive reactions.
\end{abstract}

\section{INTRODUCTION}

Symptoms of human cryptosporidiosis, caused by the protozoan parasite Cryptosporidium, include watery diarrhoea, abdominal pain, low-grade fever, nausea and/or vomiting. The duration may be up to 2 weeks, and occasionally longer. Cases can be sporadic or as part of outbreaks. In the UK, guidance is for Cryptosporidium to be sought in stools from all community cases of diarrhoea, and laboratory diagnosis became notifiable in 2010 (Chalmers et al., 2010a). Routine diagnosis is mainly by recognition of oocysts in fresh, unconcentrated stools by microscopy of smears stained with either auramine phenol (AP) or modified Ziehl-Neelsen (mZN); these are the UK Standards for Microbiological Investigations (SMIs), for-

Abbreviations: $\mathrm{AP}$, auramine phenol; $\mathrm{Cl}$, confidence interval; $\mathrm{C}_{\mathrm{T}}$, cycle threshold; EIA, enzyme immunoassay; ICLF, immunochromatographic lateral flow; IFM, immunofluorescence microscopy; mZN, modified ZiehlNeelsen; SMI, Standard for Microbiological Investigations. merly known as national standard methods (Health Protection Agency, 2007). To facilitate testing, especially in larger laboratories processing more samples, an emerging trend in the UK since 2009 is the use of commercially available immunoassays, targeting either Cryptosporidium antigen alone or in combination with Giardia (Chalmers et al., 2010a). Although PCR-based assays provide sensitive and specific diagnosis of protozoan infections including Cryptosporidium (Bruijnesteijn van Coppenraet et al., 2009), they are not yet in routine diagnostic use in the UK. Most diagnostic assays permit the reporting of the presence/absence of Cryptosporidium spp., but PCR-based methods can also be used to identify the infecting species. This is useful because there are differences in epidemiology, risk factors, clinical manifestation and sequelae between species (Xiao, 2010).

There have been many publications comparing diagnostic tests for Cryptosporidium and, whilst enzyme immunoassays (EIAs) require reduced labour time and microscopy 
skills (Garcia \& Shimizu, 1997), the sensitivity and specificity when measured against immunofluorescence microscopy (IFM) varies among studies (Garcia \& Shimizu, 1997; Weitzel et al., 2006). However, there has been no direct evaluation of all assays used routinely in the $\mathrm{UK}$, where testing is common in clinical laboratories (Chalmers et al., 2010a). Comparison of assay performance among Cryptosporidium spp. has so far been limited to immunochromatographic assays, and the ability of immunology-based diagnostic assays to detect different species is uncertain (Agnamey et al., 2011). The aim of this study was to compare the diagnostic sensitivity and specificity of the assays used in the UK and their ability to detect different Cryptosporidium spp.

\section{METHODS}

Stool samples and Cryptosporidium spp. In July 2009, a panel of 259 anonymized stools was made from those submitted for diagnosis by patients with gastrointestinal symptoms to the local hospital diagnostic microbiology laboratory ( $n=109$, mostly Cryptosporidiumnegative) and those referred to the Cryptosporidium Reference Unit ( $n=150$, mostly Cryptosporidium-positive), collected within the previous 4 weeks. The only selection criterion from each laboratory was sufficient material for the study. All stools were stored without preservative in a refrigerator $\left(2-8{ }^{\circ} \mathrm{C}\right)$. Stools were categorized as true positives $(n=152)$ if Cryptosporidium was confirmed by real-time PCR of the small-subunit rRNA gene (Hadfield et al., 2011). Stools were categorized as true negatives $(n=107)$ if Cryptosporidium was not detected by real-time PCR. To confirm that oocysts as well as Cryptosporidium DNA were present in the positive panel, these were retrieved using immunomagnetic separation (Isolate; TCS Biosciences) and visualized by direct IFM (Crypto-Cel; Cellabs) (Robinson et al., 2008). This is because oocysts or their antigens are the target for all of the routine assays investigated in this study.

Testing of at least 250 samples ensured that differences in sensitivity and specificity $>10 \%$ had an $80 \%$ chance of being detected at a $5 \%$ significance level. To compare assay performance among species, the identity of the Cryptosporidium spp. in positive samples was established by real-time PCR of the small-subunit rRNA and Lib13 genes and sequencing of products where required (Hadfield et al., 2011). The panel was blind-coded, prior to testing by two experienced laboratory personnel.

Diagnostic assays. The assays to be compared were identified as those found to be in greatest use in the UK from a survey of contemporaneous diagnostic practice (Chalmers et al., 2010a) and a UK market survey. The assays were: $\mathrm{mZN}$ staining and microscopic examination of 50 fields at $\times 500$ magnification (an SMI) (Health Protection Agency, 2007); AP staining and microscopic examination of 50 fields at $\times 200$ magnification (an SMI) (Health Protection Agency, 2007); direct IFM by examination of a $10 \mathrm{~mm}$ diameter well at $\times 200$ magnification (Crypto-Cel; CelLabs) (Robinson et al., 2008); three Cryptosporidium/Giardia combination EIA kits: Remel ProSpecT Giardia/Cryptosporidium Microplate Assay (Thermo Fisher Scientific), IVD Research Giardia/Crypto Combo EIA (Launch Diagnostics) and Giardia/Cryptosporidium CHEK (Alere); and an immunochromatographic lateral flow (ICLF) Cryptosporidium assay (RIDAQUICK Cryptosporidium cassette; R Biopharm Rhône). Another EIA (RIDASCREEN Cryptosporidium; R Biopharm Rhône) used in one UK laboratory was not evaluated because of limited stool volumes.
To reflect routine diagnostic practice, each test was performed once on each sample. Cryptosporidium direct IFM results were recorded using an arbitrary scoring system for the number of oocysts seen in each well (Table 1). Commercially available assays were conducted following the manufacturers' instructions, and the EIAs were carried out using an automated processing system (Dynex DS2; Alere). Positive ICLF and EIA reactions were confirmed, and EIAs were resolved for Cryptosporidium or Giardia using individual genusspecific IFM reagents (Cellabs) applied to air-dried and methanolfixed test suspensions on multiwell slides. The confirmed results were used in statistical analyses.

Statistical analysis. The sensitivity and specificity [with $95 \%$ confidence intervals (CIs)] for Cryptosporidium were calculated using CI Analysis (CIA) software, version 2 (University of Southampton, UK). Overlapping CIs were subjected to tests of paired proportions. The differences in median real-time PCR threshold cycle $\left(C_{\mathrm{T}}\right)$ values in true-positive samples between diagnostic assay-positive and -negative results were calculated for each assay using a MannWhitney $U$ test. The results for samples containing Cryptosporidium hominis and Cryptosporidium parvum were compared for each assay by Yates' corrected $\chi^{2}$ test. $P<0.05$ was considered statistically significant. Giardia data were considered in this study only to assess whether there were false positives in the combination assays; the collection of sufficient samples for diagnostic sensitivity and specificity assessment was outside the scope of this work.

\section{RESULTS AND DISCUSSION}

\section{Diagnostic sensitivity and specificity for Cryptosporidium}

Varying numbers of samples were positive by each of the diagnostic Cryptosporidium assays (Table 1). Comparing the $95 \% \mathrm{CI}$ for sensitivity, there was overlap between the three EIA kits (range 91.4-93.4\%), AP (92.1\%) and Crypto-Cel IFM (97.4\%) (Table 1). However, greater sensitivity of Crypto-Cel IFM was demonstrated because the paired test of proportions performed with the next closest test, the Techlab EIA, was significantly different $(P=0.01)$. The sensitivity of the RIDAQUICK ICLF assay $(84.9 \%)$ was lower than those of the EIAs and AP microscopy, but the CIs overlapped; however, this test was significantly less sensitive than IFM (97.4\%) (Table 1 ). The sensitivity of the RIDAQUICK ICLF reported here is similar to that found by Weitzel et al. (2006). mZN microscopy was significantly less sensitive than all other tests (Table 1); when mZN and ICLF were compared by a paired test of proportions, the difference was significant $(P=0.0016)$. A large percentage of cryptosporidiosis cases ( $24 \%$ for $\mathrm{mZN}$ and $15 \%$ for ICLF) would not have been diagnosed using these assays.

Of the 152 true-positive samples, 102 were positive by all seven Cryptosporidium assays and 50 were negative by one or more assays; only one sample was negative by all seven assays. This sample had a high $C_{\mathrm{T}}$ value (39.80), indicating that only a small amount of Cryptosporidium DNA was present. Discordant results were associated mainly with false negatives by mZN microscopy: 22 samples were negative by this method compared with only three by the 
Table 1. Sensitivity and specificity of Cryptosporidium assays in diagnostic stools and comparison of Cryptosporidium quantification NA, Not applicable.

\begin{tabular}{|c|c|c|c|c|c|c|c|}
\hline \multirow[t]{2}{*}{ Diagnostic assay } & \multirow{2}{*}{$\begin{array}{c}\text { Cryptosporidium } \\
\text { true-positive } \\
(n=152) \text { and } \\
\text { true-negative } \\
(n=107) \text { samples } \\
\begin{array}{c}\text { Confirmed } \\
\text { assay-positive; } \\
\text {-negative }\end{array}\end{array}$} & \multicolumn{2}{|c|}{$\begin{array}{l}\text { Comparison with nominated gold } \\
\text { standard in } 259 \text { samples }\end{array}$} & \multirow{2}{*}{$\begin{array}{c}\text { Direct IFM scores } \\
\text { in samples negative } \\
\text { by each assay } \\
\begin{array}{c}\text { Range (mode; } \\
\text { median) }\end{array}\end{array}$} & \multicolumn{3}{|c|}{$\begin{array}{l}\text { Median real-time PCR } C_{\mathrm{T}} \text { values in true-positive samples } \\
\text { (range) compared by Mann-Whitney } U \text { test }\end{array}$} \\
\hline & & $\begin{array}{c}\text { Percentage } \\
\text { sensitivity }(95 \% \mathrm{CI})\end{array}$ & $\begin{array}{c}\text { Percentage } \\
\text { specificity }(95 \% \mathrm{CI})\end{array}$ & & Assay-positive & Assay-negative & $P$ value \\
\hline mZN microscopy & $115 ; 107$ & $75.7(68.3-81.8)$ & $100(96.5-100)$ & $1-6(6 ; 5)$ & $29.03(18.95-38.96)$ & $29.95(19.08-39.95)$ & 0.1212 \\
\hline $\begin{array}{l}\text { RIDAQUICK } \\
\text { Cryptosporidium ICLF } \dagger\end{array}$ & $129 ; 107$ & $84.9(78.3-89.7)$ & $100(96.5-100)$ & $1-6(2 ; 2)$ & $28.64(19.00-40.00)$ & $32.65(22.84-39.80)$ & 0.0002 \\
\hline $\begin{array}{l}\text { Remel ProSpecT Giardia/ } \\
\text { Cryptosporidium } \\
\text { Microplate EIA } \dagger\end{array}$ & $139 ; 107$ & $91.4(85.9-94.9)$ & $100(96.5-100)$ & $1-5(2 ; 2)$ & $29.04(18.95-39.95)$ & $33.38(22.84-39.80)$ & 0.0014 \\
\hline AP microscopy & $140 ; 107$ & $92.1(86.7-95.4)$ & $100(96.5-100)$ & $1-5(2 ; 2)$ & $28.94(18.95-39.95)$ & $32.56(29.05-39.80)$ & 0.0029 \\
\hline $\begin{array}{l}\text { IVD Research Giardia/ } \\
\text { Crypto Combo EIA } \dagger\end{array}$ & $141 ; 107$ & $92.8(87.5-95.9)$ & $100(96.5-100)$ & $1-4(2 ; 2)$ & $29.04(18.95-39.95)$ & $33.38(27.94-39.80$ & 0.0030 \\
\hline $\begin{array}{l}\text { Techlab Giardia/ } \\
\text { Cryptosporidium CHEK } \\
\text { EIA } \dagger\end{array}$ & $142 ; 107$ & $93.4(88.3-96.4)$ & $100(96.5-100)$ & $1-4(2 ; 2)$ & $29.05(18.95-39.95)$ & $32.96(27.94-39.80)$ & 0.0086 \\
\hline Crypto-Cel IFM & $148 ; 107$ & $97.4(93.4-99.0)$ & $100(96.5-100)$ & $\mathrm{NA}$ & $29.40(18.95-39.95)$ & $31.98(29.52-39.80)$ & 0.0822 \\
\hline
\end{tabular}

${ }^{*}$ IFM score: 1 , oocysts not seen; 2 , one oocyst seen in each $10 \mathrm{~mm}$ microscopy slide well; 3 , two to five oocysts; 4 , six to ten oocysts; 5 , 11-50 oocysts; 6 , $>50$ oocysts.

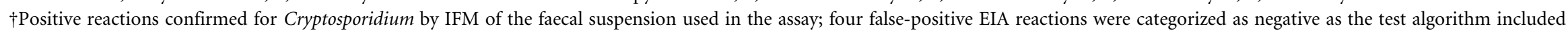
confirmation of positive reactions. 
RIDAQUICK ICLF assay and one by AP microscopy. Neither IFM nor any of the EIAs was negative when all other assays (ICLF, and mZN and AP microscopy) were positive. The other 23 samples with discordant results showed no association with any one assay. Poor sensitivity of acid-fast microscopy has been reported previously (Johnston et al., 2003); slide preparation, parasite density and variable oocyst staining, as well as time spent examining the slide, contribute to the lower detection rates in routine testing. We found higher IFM scores in samples remaining undiagnosed by this method compared with other methods (Table 1), indicating that slide examination is a particular problem for mZN microscopy where parasites are less readily observed under routine diagnostic conditions.

There was a linear relationship between increasing IFM scores (indicating more oocysts present) and decreasing real-time PCR $C_{\mathrm{T}}$ values (indicating more Cryptosporidium DNA present) (data not shown). For the true-positive samples, Mann-Whitney $U$ tests showed significantly lower real-time PCR $C_{\mathrm{T}}$ values in those positive by AP microscopy, the three EIAs and the ICLF assay, compared with samples negative by these assays $(P<0.05)$ (Table 1$)$. There was no significant difference in $C_{\mathrm{T}}$ values between true-positive samples that were positive and those that were negative by mZN microscopy $(P=0.1212)$ or by IFM $(P=0.0822)$ (Table 1$)$. Oocysts were not detected in only four true-positive samples by IFM. For mZN microscopy, the lack of difference between test outcome and $C_{\mathrm{T}}$ values probably supports the general difficulties in observing parasites by mZN microscopy under routine diagnostic conditions that are not solely due to parasite density.

In our test algorithm, which included resolution and confirmation of positive combined Cryptosporidium and Giardia EIA reactions using genus-specific IFM reagents, observed diagnostic specificities for all assays were $100 \%$ (Table 1), and the positive predictive value of the assays would be high where high specificity is achieved. Specificity may be lower for microscopy testing in laboratories with less experience at observing oocysts and differentiating other organisms and staining artefacts. The choice of test used to confirm positive ICLF and EIA reactions and resolve the organism(s) present in combined parasite assays is important and should have high sensitivity and specificity; we used IFM. Two samples that gave positive reactions in the Techlab Giardia/Cryptosporidium CHEK EIA, one other sample giving a positive reaction in the IVD Research Giardia/ Crypto Combo EIA and one other sample giving a positive reaction in the Remel ProSpecT Giardia/Cryptosporidium Microplate EIA remained unconfirmed for either parasite by IFM and were negative in all other assays. These must be considered false-positive reactions and highlight the importance of confirmatory testing. Giardia spp. were not seen in any samples by the SMIs, but were confirmed by IFM in up to two additional samples detected by each of the combination EIA kits, which concurs with improved diagnosis of Giardia infections facilitated by EIA, reported by Ellam et al. (2008). Technical problems have been reported previously with first-generation Cryptosporidium EIAs (Gradus et al., 1996) leading to false-positive results, the occurrence of which was reduced following product correction (Doing et al., 1999). Using automated platewashing and -reading equipment and highly specific assays to confirm positive results, our results showed increased sensitivity and specificity for the ProSpecT EIA compared with those reported by Johnston et al. (2003). However, as highlighted previously by Weitzel et al. (2006), comparisons may also be influenced by the study population from which the samples are drawn, the study design - especially in the size and power of the study - and in the nomination of a gold standard, as a true standard is lacking. The requirement to confirm and resolve the genus (Cryptosporidium and/or Giardia) in combination assays adds assurance, and single assays should likewise be confirmed. This is especially important to eliminate false positives (Doing et al., 1999; Weitzel et al., 2006).

\section{Detection of Cryptosporidium spp.}

Of the 152 'true positives', 80 were C. hominis, 68 C. parvum, two Cryptosporidium felis, one Cryptosporidium ubiquitum and one Cryptosporidium meleagridis, a distribution reflecting that found contemporaneously in the UK (Elwin et al., 2011), where nearly all primary diagnostic testing is undertaken by AP or mZN microscopy (Chalmers et al., 2010a). There was no significant difference between detection rates of $C$. parvum and $C$. hominis by the seven

Table 2. Cryptosporidium detection by the seven diagnostic assays in stools containing C. parvum and C. hominis

\begin{tabular}{|c|c|c|c|c|}
\hline Diagnostic assay & $\begin{array}{l}\text { C. parvum } \\
(n=68)\end{array}$ & $\begin{array}{l}\text { C. hominis } \\
\quad(n=80)\end{array}$ & $\begin{array}{c}\text { Comparison of species detection } \\
\left(\text { Yates' corrected } \chi^{2}\right)\end{array}$ & $P$ value \\
\hline mZN microscopy & $48(70.6 \%)$ & $65(81.3 \%)$ & 1.76 & 0.1845 \\
\hline Remel ProSpecT Giardia/Cryptosporidium EIA & $65(95.6 \%)$ & $72(90.0 \%)$ & 0.96 & 0.3284 \\
\hline AP microscopy & $62(91.2 \%)$ & $76(95.0 \%)$ & 0.35 & 0.5519 \\
\hline IVD Research Giardia/Crypto Combo EIA & $66(97.1 \%)$ & $73(91.3 \%)$ & 1.27 & 0.2591 \\
\hline Crypto-Cel IFM & $67(98.5 \%)$ & $78(97.5 \%)$ & 0.02 & 0.8868 \\
\hline
\end{tabular}


Table 3. Relative attributes of the seven Cryptosporidium diagnostic assays

\begin{tabular}{|c|c|c|c|c|c|c|c|c|}
\hline $\begin{array}{l}\text { Assay or } \\
\text { format }\end{array}$ & $\begin{array}{l}\text { Diagnostic } \\
\text { sensitivity }\end{array}$ & $\begin{array}{l}\text { Diagnostic } \\
\text { specificity }\end{array}$ & Technical expertise & $\begin{array}{l}\text { Speed of } \\
\text { turnaround time }\end{array}$ & $\begin{array}{c}\text { Performed } \\
\text { in batch mode }\end{array}$ & $\begin{array}{l}\text { Hands-on } \\
\text { time }\end{array}$ & $\begin{array}{l}\text { Consumables } \\
\text { cost per test }\end{array}$ & $\begin{array}{l}\text { Specialist laboratory } \\
\text { equipment required }\end{array}$ \\
\hline mZN microscopy & Moderate & $\begin{array}{l}\text { Moderate - } \\
\text { need to } \\
\text { differentiate } \\
\text { staining artefacts } \\
\text { and other } \\
\text { organisms }\end{array}$ & $\begin{array}{l}\text { High degree of } \\
\text { interpretation } \\
\text { and continued } \\
\text { practice required }\end{array}$ & Good & $\begin{array}{l}\text { Only for } \\
\text { staining slides }\end{array}$ & $\begin{array}{l}\text { Highly labour- } \\
\text { intensive }\end{array}$ & Low & $\begin{array}{l}\text { Bright-field } \\
\text { microscope } \\
\text { with good } \\
\text { optics }\end{array}$ \\
\hline ICLF & Moderate & Good & Simple to perform & $\begin{array}{l}\text { Excellent } \\
(<10 \mathrm{~min})\end{array}$ & No & $\begin{array}{l}\text { Not labour- } \\
\text { intensive }\end{array}$ & High & None \\
\hline EIA & Good & $\begin{array}{l}\text { Good when used } \\
\text { with confirmatory } \\
\text { test }\end{array}$ & $\begin{array}{l}\text { Moderately simple } \\
\text { to perform }\end{array}$ & Good & Yes & $\begin{array}{l}\text { Not labour- } \\
\text { intensive }\end{array}$ & High & $\begin{array}{l}\text { Plate washer } \\
\text { and reader }\end{array}$ \\
\hline AP microscopy & Good & Good & $\begin{array}{l}\text { Moderate degree } \\
\text { of interpretation } \\
\text { and continued } \\
\text { practice required }\end{array}$ & Very good & $\begin{array}{l}\text { Only for } \\
\text { staining slides }\end{array}$ & $\begin{array}{l}\text { Moderately } \\
\text { labour- } \\
\text { intensive }\end{array}$ & Low & $\begin{array}{l}\text { Fluorescence } \\
\text { microscope } \\
\text { with good } \\
\text { optics }\end{array}$ \\
\hline $\begin{array}{l}\text { Immunofluorescence } \\
\text { microscopy }\end{array}$ & Excellent & Excellent & $\begin{array}{l}\text { Moderate degree } \\
\text { of interpretation } \\
\text { and continued } \\
\text { practice required }\end{array}$ & Very good & No & $\begin{array}{l}\text { Moderately } \\
\text { labour- } \\
\text { intensive }\end{array}$ & Moderate & $\begin{array}{l}\text { Fluorescence } \\
\text { microscope } \\
\text { with good optics }\end{array}$ \\
\hline
\end{tabular}


assays investigated (Table 2) ( $P>0.05)$, although, as far as we are aware, the antibodies in commercially available EIA and ICLF assays were raised against C. parvum. Agnamey et al. (2011) also found no difference in the detection rates of $C$. parvum and C. hominis when they compared three commercial immunochromatographic assays, including the RIDAQUICK assay that was also used in our study. The detection of other Cryptosporidium spp. in our study must be interpreted with caution as the number of samples was small. Very little information is available about the antibodies that are incorporated into each assay, and it is not known how strongly they react with the exposed epitopes on the antigens of species genetically distant from C. parvum. Furthermore, results may also be influenced by parasite density. The $C$. meleagridis isolate was detected by all seven assays and had a high IFM score of 6 . The $C$. ubiquitum isolate was not detected by $\mathrm{mZN}$ microscopy, even though the IFM score was high (score of 5), but it was detected by all other assays. Of the two $C$. felis isolates, one was detected by IFM only (score of 2 ) and the other by mZN microscopy only, but they were not detected by the six other assays. This is in agreement with the results of Agnamey et al. (2011) who found imperfect detection of C. felis by immunochromatographic assays. They also reported a lack of detection of C. meleagridis, Cryptosporidium canis and an undefined Cryptosporidium sp. using these assays, but again the numbers of samples tested were small and the parasite density was not reported (Agnamey et al., 2011). However, since our study was undertaken, more laboratories in the UK are now using EIA and ICLF assays as their primary test, and we continue to identify 'unusual' Cryptosporidium spp. in positive stools submitted from these laboratories as well as from those using conventional microscopy (Cryptosporidium Reference Unit, unpublished data). We have also confirmed, using molecular methods, a variety of Cryptosporidium spp. in water samples, originally isolated using immunomagnetic separation and detected by IFM (Chalmers et al., 2010b; Robinson et al., 2011), suggesting that the antibodies in these tests have broad species specificity. Although cross-reactivity of several antibodybased tests has been demonstrated (Barugahare et al., 2011), the species specificity of antibody-based Cryptosporidium assays requires further investigation and this is under way at the Cryptosporidium Reference Unit.

In conclusion, whilst IFM offered the best diagnostic sensitivity compared with our nominated gold standard, this microscopy-based test is more expensive than mZN and AP microscopy and requires a fluorescence microscope, trained staff and more hands-on time per sample than nonmicroscopy-based methods (Table 3). The ICLF format eliminates the need for skilled technical staff and specialized equipment and offers a rapid diagnosis (Table 3 ), but is less sensitive than EIAs (Table 1). The EIAs tested here offer an alternative to traditional diagnostic tests and may expand or enable continued testing of a high proportion of acute diarrhoea cases for Cryptosporidium, as the tests can be undertaken in batches (Table 3) (Chalmers et al., 2010a).
They have been used to expand patient testing for Giardia, which is often restricted to patients with foreign travel history, with beneficial results (Ellam et al., 2008). Although specialist equipment (plate washers and readers) is required to automate the process (Table 3 ), this must be validated locally, and diagnostic algorithms must include confirmation of positive reactions. The higher cost of the immunoassay kits may be offset by reduced labour costs, but a skill base needs to be maintained for confirmation. Accurate and prompt diagnosis of diarrhoeal illness is essential for individual patient management and specific control interventions.

\section{ACKNOWLEDGEMENTS}

We thank the various companies for supplying the test kits and technical support. The assays that we compared were those found to be in greatest use in the UK from a survey of contemporaneous diagnostic practice (Chalmers et al., 2010a) and a UK market survey. Use of trade names and commercial sources is for identification only and does not imply endorsement by Swansea University or Public Health Wales. Thanks are also extended to Catherine Shepherd, Sharon Poynton and the staff of the Enteric Laboratory in Public Health Wales Microbiology ABM for facilitating this study and to Dr Stephen Hadfield of the Cryptosporidium Reference Unit for providing the real-time PCR data.

\section{REFERENCES}

Agnamey, P., Sarfati, C., Pinel, C., Rabodoniriina, M., Kapel, N., Dutoit, E., Garnaud, C., Diouf, M., Garin, J.-F. \& other authors (2011). Evaluation of four commercial rapid immunochromatographic assays for detection of Cryptosporidium antigens in stool samples: a blind multicenter trial. J Clin Microbiol 49, 1605-1607.

Barugahare, R., Dennis, M. M., Becker, J. A. \& Šlapeta, J. (2011). Detection of Cryptosporidium molnari oocysts from fish by fluorescent-antibody staining assays for Cryptosporidium spp. affecting humans. Appl Environ Microbiol 77, 1878-1880.

Bruijnesteijn van Coppenraet, L. E., Wallinga, J. A., Ruijs, G. J., Bruins, M. J. \& Verweij, J. J. (2009). Parasitological diagnosis combining an internally controlled real-time PCR assay for the detection of four protozoa in stool samples with a testing algorithm for microscopy. Clin Microbiol Infect 15, 869-874.

Chalmers, R. M., Campbell, B., Crouch, N. \& Davies, A. P. (2010a). Clinical laboratory practices for the detection and reporting of Cryptosporidium in community cases of diarrhoea in the United Kingdom, 2008. Euro Surveill 15, pii=19731.

Chalmers, R. M., Robinson, G., Elwin, K., Hadfield, S. J., Thomas, E., Watkins, J., Casemore, D. \& Kay, D. (2010b). Detection of Cryptosporidium species and sources of contamination with Cryptosporidium hominis during a waterborne outbreak in north west Wales. J Water Health 8, 311-325.

Doing, K. M., Hamm, J. L., Jellison, J. A., Marquis, J. A. \& Kingsbury, C. (1999). False-positive results obtained with the Alexon ProSpecT Cryptosporidium enzyme immunoassay. J Clin Microbiol 37, 1582-1583.

Ellam, H., Verlander, N. Q., Lamden, K., Cheesbrough, J. S., Durband, C. A. \& James, S. (2008). Surveillance of giardiasis in Northwest England 1996-2006: impact of an enzyme immunoassay test. Euro Surveill 13, pii $=18977$.

Elwin, K., Hadfield, S. J., Robinson, G. \& Chalmers, R. M. (2011). The epidemiology of sporadic human infections with unusual cryptosporidia 
detected during routine typing in England and Wales, 2000-2008. Epidemiol Infect (in press). http://dx.doi.org/10.1017/S0950268811000860

Garcia, L. S. \& Shimizu, R. Y. (1997). Evaluation of nine immunoassay kits (enzyme immunoassay and direct fluorescence) for detection of Giardia lamblia and Cryptosporidium parvum in human fecal specimens. J Clin Microbiol 35, 1526-1529.

Gradus, M. S., Bullock-lacullo, S., Garcia, L. S., Kaplan, R. L., Smith, J. W., Tran, T. \& Zabransky, R. J. (1996). Cryptosporidiosis: a continuing challenge for the clinical and public health microbiologist: strategies for proactive detection of waterborne cryptosporidiosis by clinical and public health microbiology laboratories. Clin Microbiol Newsl 18, 185-190.

Hadfield, S. J., Robinson, G., Elwin, K. \& Chalmers, R. M. (2011). Detection and differentiation of Cryptosporidium spp. in human clinical samples by use of real-time PCR. J Clin Microbiol 49, 918-924.

Health Protection Agency (2007). Investigation of Dermatological Specimens for Superficial Mycoses (BSOP 39). http://www.hpastandardmethods.org.uk/documents/bsop/pdf/bsop39.pdf
Johnston, S. P., Ballard, M. M., Beach, M. J., Causer, L. \& Wilkins, P. P. (2003). Evaluation of three commercial assays for detection of Giardia and Cryptosporidium organisms in fecal specimens. J Clin Microbiol 41, 623-626.

Robinson, G., Watkins, J. \& Chalmers, R. M. (2008). Evaluation of a modified semi-automated immunomagnetic separation technique for the detection of Cryptosporidium oocysts in human faeces. J Microbiol Methods 75, 139-141.

Robinson, G., Chalmers, R. M., Stapleton, C., Palmer, S. R., Watkins, J., Francis, C. \& Kay, D. (2011). A whole water catchment approach to investigating the origin and distribution of Cryptosporidium species. J Appl Microbiol 111, 717-730.

Weitzel, T., Dittrich, S., Möhl, I., Adusu, E. \& Jelinek, T. (2006). Evaluation of seven commercial antigen detection tests for Giardia and Cryptosporidium in stool samples. Clin Microbiol Infect 12, 656659.

Xiao, L. (2010). Molecular epidemiology of cryptosporidiosis: an update. Exp Parasitol 124, 80-89. 